\title{
Effect of dynamic plastic deformation on microstructure and annealing behaviour of modified $9 \mathrm{Cr}-1$ Mo steel
}

\author{
Zhang, Zhenbo; Mishin, Oleg V.; Tao, N. R.; Pantleon, Wolfgang
}

Published in:

Materials Science and Technology

Link to article, DOI:

$10.1179 / 1743284714 Y .0000000652$

Publication date:

2015

Document Version

Peer reviewed version

Link back to DTU Orbit

Citation (APA):

Zhang, Z., Mishin, O. V., Tao, N. R., \& Pantleon, W. (2015). Effect of dynamic plastic deformation on microstructure and annealing behaviour of modified 9Cr-1Mo steel. Materials Science and Technology, 31(6), 715-721. https://doi.org/10.1179/1743284714Y.0000000652

\section{General rights}

Copyright and moral rights for the publications made accessible in the public portal are retained by the authors and/or other copyright owners and it is a condition of accessing publications that users recognise and abide by the legal requirements associated with these rights.

- Users may download and print one copy of any publication from the public portal for the purpose of private study or research.

- You may not further distribute the material or use it for any profit-making activity or commercial gain

- You may freely distribute the URL identifying the publication in the public portal 


\title{
Effect of dynamic plastic deformation on the microstructure and annealing behavior of a modified $9 \mathrm{Cr}-1 \mathrm{Mo}$ steel
}

\author{
Z.B. Zhang, ${ }^{* 1,4}$ O.V. Mishin, ${ }^{1,4}$ N.R. Tao, ${ }^{2,4}$ and W. Pantleon ${ }^{3,4}$ \\ ${ }^{1}$ Danish-Chinese Center for Nanometals, Section for Materials Science and Advanced \\ Characterization, Department of Wind Energy, Technical University of Denmark, Risø Campus, \\ 4000 Roskilde, Denmark \\ ${ }^{2}$ Institute of Metal Research, Chinese Academy of Science, 110016 Shenyang, China \\ ${ }^{3}$ Section for Materials and Surface Engineering, Department of Mechanical Engineering, \\ Technical University of Denmark, 2800 Kgs. Lyngby, Denmark \\ ${ }^{4}$ Sino-Danish Center for Education and Research
}

Keywords: ferritic/martensitic steel; dynamic plastic deformation; quasi-static compression; annealing

\begin{abstract}
The effect of dynamic plastic deformation on the microstructure of a modified $9 \mathrm{Cr}-1 \mathrm{Mo}$ steel has been investigated in comparison with the effect of quasi-static compression. It is found that after $40 \%$ deformation the boundary spacing after dynamic plastic deformation is smaller and the hardness is higher than those after quasi-static compression. The microstructure after dynamic plastic deformation is however less stable than the microstructure after quasi-static compression. Annealing at $675^{\circ} \mathrm{C}$ and $700^{\circ} \mathrm{C}$ leads to structural coarsening and recrystallization in each sample, but with recrystallization occurring faster in the sample annealed after dynamic plastic deformation. The lower thermal stability of the microstructure produced by dynamic plastic deformation is attributed to a higher driving force for recrystallization in the dynamically deformed material.
\end{abstract}




\section{Introduction}

Ferritic/martensitic steels containing 9 to $12 \mathrm{wt} . \% \mathrm{Cr}$ are used as structural materials for power plant steam generators, ${ }^{1,2}$ and are also considered to be candidate structural materials for advanced fission and fusion reactors. ${ }^{3,4}$ Such materials must be resistant to irradiation induced swelling and retain high strength at elevated temperatures. It has been reported that improved irradiation tolerance may be achieved in materials with well-refined microstructures. ${ }^{5,6}$ Since materials with well-refined microstructures are also characterized by high $\operatorname{strength}^{7}$, a study of structural refinement in steels is of significant interest. One way to effectively refine the microstructure is by plastic deformation. It has, for example, been shown that significant structural refinement can be achieved in a low-carbon martensitic steel by cold rolling to a reduction of only $50 \% .{ }^{8,9}$, with the initial martensitic structure being transformed during rolling into a typical dislocation cell-block structure. ${ }^{10,11}$ It is expected that plastic deformation at higher strain rates than those applied during conventional rolling can refine the microstructure to an even greater extent. ${ }^{12}$ An example of such a high strain rate process is dynamic plastic deformation (DPD), where a hammer falls from a certain height and impacts a specimen, which becomes compressed at strain rates of about $10^{2} \mathrm{~s}^{-1}$ to $10^{3} \mathrm{~s}^{-1} 13,14$. For $\mathrm{Ni}$ and $\mathrm{Al}$, it has been reported that DPD was more effective in refining the microstructure than deformation at lower strain rates and that this refinement was accompanied by a high frequency of dislocation boundaries with low misorientation angles across them. ${ }^{15,16}$

As a result of the differences between deformed microstructures produced at different strain rates, the annealing behavior of DPD-processed materials may also be different from that observed during annealing of materials deformed at conventional strain rates. Therefore, in the present work, we focus on studying changes in the microstructure, texture and hardness of a $9 \mathrm{Cr}-1 \mathrm{Mo}$ steel both during DPD and subsequent annealing. Furthermore, to evaluate the effect of the strain rate, the data obtained for a DPD sample are compared with those in a sample produced by quasi-static deformation (QSC). To enable a detailed analysis of structural parameters both transmission electron microscopy (TEM) and electron backscatter diffraction (EBSD) techniques are used in this work. 


\section{Experimental}

The chemical composition of the modified $9 \mathrm{Cr}-1 \mathrm{Mo}$ steel (X10CrMoVNb9-1) determined by glow discharge optical emission spectroscopy is shown in Table 1. The material was supplied by Remystahl Gmbh \& Co KG in the form of a hot-extruded rod, normalized at $1040{ }^{\circ} \mathrm{C}$ for $1.4 \mathrm{~h}$, tempered at $770{ }^{\circ} \mathrm{C}$ for $5 \mathrm{~h}$ and finally stress-relieved at $740{ }^{\circ} \mathrm{C}$. Cylindrical specimens with the cylinder axis along the extrusion direction (ED) of the as-received rod, and a size of $9 \mathrm{~mm}$ in diameter and $12 \mathrm{~mm}$ in height, were machined for QSC and DPD. The strain rates applied were $10^{-4} \mathrm{~s}^{-1}$ for QSC and $10^{2}-10^{3} \mathrm{~s}^{-1}$ for DPD. Each sample was compressed $40 \%$ at room temperature. The deformed samples were annealed at either $675^{\circ} \mathrm{C}$ or $700{ }^{\circ} \mathrm{C}$ for $1 \mathrm{~h}$. These heat-treatments were selected (based on Vickers hardness measurements) from a preliminary study covering a broad range of annealing treatments to obtain conditions representing different stages of recrystallization.

The microstructure was investigated in a section that contained the ED for the as-received sample, and the compression axis (CA) for the DPD and QSC samples. In the present work, both $\mathrm{ED}$ and CA are collectively termed the normal direction (ND). For each sample, the central part was inspected by both EBSD and TEM. Local orientations were measured in a Zeiss Supra 35 field emission gun scanning electron microscope equipped with the Channel 5 EBSD system from HKL Technology. A step size of $50 \mathrm{~nm}$ was chosen for characterizing the deformed microstructure using EBSD. Larger step sizes $(0.1 \mu \mathrm{m}$ or $0.2 \mu \mathrm{m})$ were used for texture analysis and for microstructural characterization of the annealed samples. For each sample, microstructural parameters were measured in several maps covering a total area of $3000-$ $4000 \mu \mathrm{m}^{2}$ in the deformed conditions and $20000-100000 \mu \mathrm{m}^{2}$ in the as-received material and annealed conditions. For texture analysis the area covered was at least $1.0 \mathrm{~mm}^{2}$ in each sample. The EBSD indexing rate was about $83 \%$ for the deformed samples. For the other samples, the EBSD indexing rate varied between $88 \%$ and $96 \%$. During post-processing of the orientation maps, pixels with non-indexed orientations were assigned orientations of neighboring pixels using the standard filtering procedure available in the Channel 5 software.

Boundaries in the orientation maps were identified based on the misorientation between adjacent orientations: high angle boundaries (HABs) were defined as those with misorientation angles above $15^{\circ}$, whereas boundaries with misorientation angles between $2^{\circ}$ and $15^{\circ}$ were 
defined as low angle boundaries (LABs). Martensite block boundaries (MBBs) were identified as follows: from the 24 possible variants derived from the Kurdjumov-Sachs relationship, ${ }^{17,18}$ only the orientation relationships (ORs) between martensite blocks in the same packet, i.e. having the same habit plane, and having high misorientation angles were considered, namely $60^{\circ}\langle 111\rangle$, $60^{\circ}\langle 110\rangle$, and $49.5^{\circ}\langle 110\rangle$. Boundaries with misorientations deviating by less than $5^{\circ}$ from these particular ORs were classified as MBBs. Average boundary spacings $d$ for different boundary types were obtained by the linear intercept method. In this work, we report the boundary spacings only along the ND because for all the deformed and annealed samples the average boundary spacing along the orthogonal direction was proportional to the spacing along the ND by a factor of $1.5-1.7$. Only for the as-received material was this ratio different with a value of 1.1. For identification of recrystallized grains in the EBSD data, the following approach was used: an individual region was considered recrystallized if all misorientations within this region were less than $2^{\circ}$, its area was larger than $7 \mu \mathrm{m}^{2}$ and the region was at least partially surrounded by HABs. TEM images were taken using a JEOL 2000 FX microscope, and selected area diffraction patterns were analyzed to determine types of particles present in the microstructure. Vickers hardness tests were performed in the center of the samples using a load of $1 \mathrm{~kg}$ with a dwell time of $10 \mathrm{~s}$.

\section{Results}

\section{As-received material}

A tempered martensite structure is observed in the as-received material (see Fig. 1), in which $\mathrm{M}_{23} \mathrm{C}_{6}$ particles are mainly located at prior austenite grain boundaries and martensitic boundaries. A misorientation map obtained by ESBD from this material is shown in Fig. 2a, where LABs, HABs and MBBs are shown as gray, black and red lines, respectively. The MBBs contribute to a large fraction of boundaries with misorientation angles above $40^{\circ}$, which - along with the LABs developed during tempering of martensite ${ }^{4}$ - result in a bimodal distribution of misorientation angles (see Fig. 3a). The average spacing between MBBs $\left(d_{\mathrm{MBB}}\right)$ along the ND in this as-received microstructure is $7.5 \mu \mathrm{m}$. Taking into account that the average HAB spacing ( $\left.d_{\mathrm{HAB}}\right)$ measured along the ND is $2.4 \mu \mathrm{m}$ and that the average spacing between all boundaries, $d_{\left(\theta>2^{\circ}\right)}$, identified 
from the EBSD data is $1.1 \mu \mathrm{m}$ (see Table 2), at least $32 \%$ of the HABs and $15 \%$ of all boundaries are considered to be MBBs. The boundary spacing determined between only LABs $\left(d_{\mathrm{LAB}}\right)$ is $2 \mu \mathrm{m}$. The as-received sample contains a weak $\langle 110\rangle$ fiber texture along the ND (Fig. 4a). The hardness of this sample is $205 \pm 2$ HV1.

\section{Deformed samples}

During compression grains flatten, the dislocation density increases and new cell boundaries are produced. Therefore, the boundary spacings decrease significantly compared to those in the asreceived condition and the frequency of LABs becomes higher (Fig. 2b). After DPD the spacing $d_{\left(\theta>2^{\circ}\right)}$ decreases from $1.1 \mu \mathrm{m}$ to only $210 \mathrm{~nm}$. The value of $210 \mathrm{~nm}$ is slightly above the spacing $d$ measured between all boundaries observed in TEM images, $190 \mathrm{~nm}$ (see Fig. 5a). Significant reductions are also observed for $d_{\mathrm{LAB}}$ and $d_{\mathrm{HAB}}$ (see Table 2). In contrast, $d_{\mathrm{MBB}}$ becomes greater after deformation as the frequency of MBBs in the compressed samples becomes very low $(2 \%$ after DPD and 3\% after QSC).

Compared to the DPD sample, the microstructure of the QSC sample is less refined. The boundary spacings $d_{\left(\theta>2^{\circ}\right)}$ and $d$ measured using either EBSD (Fig. 2c) or TEM (see Fig. 5b) for the QSC sample are $290 \mathrm{~nm}$ and $240 \mathrm{~nm}$, respectively, which are larger than the corresponding values for the DPD sample. The values of $d_{\mathrm{LAB}}, d_{\mathrm{HAB}}$ and $d_{\mathrm{MBB}}$ for the QSC sample are also appreciably larger than those recorded for the DPD sample (see Table 2).

The misorientation angle distributions for the DPD and QSC samples are generally similar (see Fig. $3 \mathrm{~b}$ and c), though the LAB fraction is slightly higher in the DPD sample (77\%) than in the QSC sample (71\%). In contrast to the as-received condition, the frequency of misorientation angles above $40^{\circ}$ is very low in the compressed samples (see Fig. 3). A duplex $\langle 111\rangle+\langle 100\rangle$ texture is observed in both deformed samples (see Fig. 4) being slightly stronger in the DPD sample. In addition, the DPD sample is about $12 \%$ harder than the QSC sample (see Table 2).

\section{Annealed samples}

Annealing at $675^{\circ} \mathrm{C}$ for $1 \mathrm{~h}$ results in coarsening of the deformed microstructure and in the onset of recrystallization (Fig. 6). The $d_{\left(\theta>2^{\circ}\right)}$ increases to approximately $0.4 \mu \mathrm{m}$. This value, however, also includes a contribution from recrystallized grains, which after this annealing treatment 
occupy an area fraction $\left(f_{\mathrm{RX}}\right)$ of $2 \%$ and $8 \%$ in the QSC and DPD samples, respectively. After annealing at $700{ }^{\circ} \mathrm{C}$ for $1 \mathrm{~h}, f_{\mathrm{RX}}$ is still rather small $(6 \%)$ in the QSC sample, whereas the DPD sample is almost fully (95\%) recrystallized (see Fig. 7 and Table 2).

To obtain information on just the non-recrystallized (recovered) regions of the annealed samples, spacings between $\mathrm{LABs}$ were calculated excluding the contribution of the recrystallized regions. The resulting parameter $d^{*} \mathrm{LAB}$ is inversely proportional to the surface area density $S_{V}$ of LABs in the recovered regions, and an increase in $d^{*} \mathrm{LAB}$ thus characterizes the elimination of LABs during recovery of the deformed material. After annealing at $675^{\circ} \mathrm{C}$ for $1 \mathrm{~h}, d^{*} \mathrm{LAB}$ is larger than $d_{\mathrm{LAB}}$ in the deformed microstructure by $60 \%$ and $130 \%$ for the QSC and DPD samples, respectively. This indicates that recovery is more pronounced in the DPD sample. Nevertheless, the recovered microstructure in the DPD sample is still more refined than that in the QSC sample (see $d^{*}$ LAB in Table 2). The difference between the samples is much greater in the material annealed at $700{ }^{\circ} \mathrm{C}$ for $1 \mathrm{~h}$, where the ratios between $d^{*} \mathrm{LAB}$ and $d_{\mathrm{LAB}}$ in the deformed microstructure are almost 5 and 2 after DPD and QSC, respectively. It should however be noted that only a very small area (5\%), classified as recovered, contributed to $d^{*}{ }_{\mathrm{LAB}}$ for the DPD sample annealed at $700{ }^{\circ} \mathrm{C}$. Therefore, statistics for this value in the latter condition are not as good as for the other annealed samples.

Considering the fraction of $\mathrm{HABs}$, it is apparent that $f_{\mathrm{HAB}}$ differs very little for both annealed conditions of the QSC sample, but increases significantly with increasing annealing temperature in the DPD sample (see Table 2). Whereas annealing at $675^{\circ} \mathrm{C}$ for $1 \mathrm{~h}$ does not result in appreciable changes in crystallographic textures, in the samples annealed at $700{ }^{\circ} \mathrm{C}$ the $\langle 100\rangle$ texture weakens considerably, especially in the annealed DPD sample (see Fig. 4c).

As expected, the annealing treatments soften both deformed samples. However, in contrast to the deformed conditions, where the DPD sample was harder than the QSC sample, the annealed DPD sample is softer than the annealed QSC sample, particularly after annealing at $700{ }^{\circ} \mathrm{C}$ for $1 \mathrm{~h}$ (see Table 2$)$. 


\section{Discussion}

Modified 9Cr-1Mo steel compressed $40 \%$ via either DPD or QSC is found to develop duplex $\langle 111\rangle+\langle 100\rangle$ fiber textures similar to those reported for other bcc materials deformed by compression, ${ }^{19-21}$ and contains a well-refined microstructure due to subdivision by dislocation boundaries. The deformation is also found to result in a reduction in the frequency of MBBs as compared to that in the as-received condition. Whereas $15 \%$ of all boundaries (almost one third of all $\mathrm{HABs}$ ) in the as-received condition were identified as MBBs, the MBB fraction becomes negligibly small after deformation. Apparently, orientation changes induced by compression destroy to a large extent the ORs existing in the as-received condition, which results in a further decrease in the frequency of MBBs both in the DPD and QSC samples. Recovery causes further loss of the three investigated ORs and a slight increase of the MBB spacing (cf. $d_{\mathrm{MBB}}$ in the deformed samples and $d^{*}$ MBB in Table 2, calculated excluding the recrystallized regions by analogy with $d^{*}$ LAB $)$. Only a few boundaries with the selected ORs remain after extensive recrystallization at $700{ }^{\circ} \mathrm{C}$ in the DPD sample (see Fig. 7a and Table 2).

An important result of the present work is the observation that the strain rate has a considerable effect on microstructural parameters of the given steel. The microstructure of the DPD sample is more refined by dislocation boundaries, and this greater refinement makes the DPD sample harder than the QSC sample. This result obtained on the $b c c$ material is in conflict with previous findings in pure iron ${ }^{22}$, but similar to those previously reported for $f c c$ nickel and aluminum, ${ }^{15,16}$ for which the greater refinement after DPD was rationalized based on a higher density of dislocations stored after high strain rate deformation. Such a higher dislocation density results in a higher frequency of dislocation boundaries and in finer boundary spacing than those in the QSC material. ${ }^{15,16}$ Similarly, a larger amount of stored dislocations can explain the greater refinement observed in the DPD-processed steel investigated here, as compared to the QSC counterpart.

Comparing the average boundary spacings in the deformed microstructure analyzed using either TEM or EBSD, it is found that the values obtained by EBSD are $10-20 \%$ greater than those obtained by TEM. Apparently, this difference is due to the fact that misorientation angles less than $2^{\circ}$ were ignored in the ESBD data. Although the subgrain size, mean misorientation angle and fraction of HABs in the deformed microstructure are typically overestimated by 
EBSD ${ }^{23,24}$ the EBSD data collected in the present experiment nevertheless correctly capture the principal difference between the samples. It is important that both the TEM and EBSD data consistently demonstrate that the boundary spacing is finer in the DPD sample. This finer spacing explains the higher hardness of the DPD sample, and implies - as the surface area density of boundaries is higher - that the energy stored during high strain rate deformation is greater than that after QSC.

The difference in the stored energy between the two deformed samples can explain the differences observed in their annealing behavior. It is obvious that a deformed material with a higher stored energy is more prone to recrystallization than a sample with less stored energy. It is therefore not surprising that the area fraction of recrystallized grains after each heat treatment applied in this work is greater for the samples annealed after DPD (Fig. 6, Fig. 7 and Table 2). The difference in the recrystallization kinetics is significant after annealing at $675{ }^{\circ} \mathrm{C}$ for $1 \mathrm{~h}$ and becomes very large when the annealing temperature is increased to $700{ }^{\circ} \mathrm{C}$. It is suggested that the strong dependence of the annealing behavior on the strain rate applied during processing of the modified $9 \mathrm{Cr}-1$ Mo steel should be taken into account when designing thermo-mechanical treatments for this material.

\section{Conclusions}

1. The strain rate has a significant effect on the structural refinement of a modified $9 \mathrm{Cr}-1 \mathrm{Mo}$ steel (X10CrMoVNb9-1) compressed 40\%. Compared to deformation at a low strain rate, dynamic plastic deformation generates a higher frequency of low angle boundaries and a smaller boundary spacing. The sample after dynamic plastic deformation is $12 \%$ harder than the sample after quasi-static compression.

2. During annealing at $675^{\circ} \mathrm{C}$ for $1 \mathrm{~h}$ the microstructure in both samples coarsens, and recrystallized grains appear. The area fraction of the recrystallized material is $8 \%$ in the sample annealed after dynamic plastic deformation and $2 \%$ in the sample annealed after quasi-static compression. Annealing at $675^{\circ} \mathrm{C}$ for $1 \mathrm{~h}$ does not appreciably change the fraction of high angle boundaries in the sample produced by quasi-static compression, while 
in the sample produced by dynamic plastic deformation the fraction of high angle boundaries significantly increases during annealing.

3. The difference between the two samples becomes very significant after annealing at $700{ }^{\circ} \mathrm{C}$ for $1 \mathrm{~h}$. After this annealing treatment, recrystallized grains occupy $95 \%$ of the area in the sample produced by dynamic plastic deformation, whereas the area fraction of the recrystallized material is only $6 \%$ in the sample annealed after quasi-static compression. This greater fraction in the sample annealed after dynamic plastic deformation is attributed to a higher driving force for recrystallization due to a finer spacing between dislocation boundaries in the deformed microstructure.

\section{Acknowledgements}

The financial support from the Sino-Danish Center for Education and Research is gratefully acknowledged. OVM also gratefully acknowledges the support from the Danish National Research Foundation (Grant No. DNRF86-5) and the National Natural Science Foundation of China (Grant No. 51261130091) to the Danish-Chinese Center for Nanometals.

\section{References}

1. R. Viswanathan and W. Bakker: 'Materials for ultrasupercritical coal power plants-boiler materials: Part 1', J. Mater. Eng. Perform, 2001, 10, 81-95.

2. U.A. Sachadel, P.F. Morris and P.D. Clarke: 'Design of $10 \% \mathrm{Cr}$ martensitic steels for improved creep resistance in power plant applications', Mater. Sci. Technol, 2013, 29, $767-774$.

3. F.S. Huang and M.L. Hamilton: 'The fracture toughness database of ferritic alloys irradiated to very high neutron exposures', J. Nucl. Mater., 1992, 187, 278-293.

4. R.L. Klueh: 'Elevated temperature ferritic and martensitic steels and their application to future nuclear reactors', Int. Mater. Rev., 2005, 50, 287-310.

5. G.R. Odette, M.J. Alinger and B.D. Wirth: 'Recent developments in irradiation-resistant steels', Annu. Rev. Mater. Res., 2008, 38, 471-503. 
6. X.M. Bai, A.F. Voter, R.G. Hoagland, M. Nastasi and B.P. Uberuaga: 'Efficient annealing of radiation damage near grain boundaries via interstitial emission', Science, 2010, 327, $1631-1634$.

7. R. Song, D. Ponge, D. Raabe, J.G. Speer and D.K. Matlock: 'Overview of processing, microstructure and mechanical properties of ultrafine grained bcc steels', Mater. Sci. Eng. A, 2006, 441, 1-17.

8. R. Ueji, N. Tsuji, Y. Minamino and Y. Koizumi: 'Ultragrain refinement of plain low carbon steel by cold rolling and annealing of martensite', Acta Mater., 2002, 50, 4177-4189.

9. X. Huang, S. Morito, N. Hansen and T. Maki: 'Ultrafine structure and high strength in coldrolled martensite', Metall. Mater. A, 2012, 43, 3517-3531.

10. N. Hansen: 'Cold deformation microstructures'. Mater. Sci. Technol., 1990, 11, 1039-1047.

11. N. Hansen and D. Juul Jensen: 'Deformed metals - structure, recrystallisation and strength', Mater. Sci. Technol., 2011, 27, 1229-1240.

12. G.T. Gray III: 'High-strain-rate deformation: mechanical behavior and deformation substructures induce'. Annu. Rev. Mater. Res., 2012, 42, 285-303.

13. Y.S. Li, N.R. Tao and K. Lu: 'Microstructural evolution and nanostructure formation in copper during dynamic plastic deformation at cryogenic temperatures', Acta Mater., 2008, 56, $230-241$.

14. F.K. Yan, G.Z. Liu, N.R. Tao and K. Lu: 'Strength and ductility of 316L austenitic stainless steel strengthened by nano-scale twin bundles', Acta Mater., 2012, 60, 1059-1071.

15. F. Huang, N.R. Tao and K. Lu: 'Effects of strain rate and deformation temperature on microstructures and hardness in plastically deformed pure aluminum', J. Mater. Sci. Technol., $2011,27,1-7$.

16. Z.P. Luo, O.V. Mishin, Y.B. Zhang, H.W. Zhang and K. Lu: 'Microstructural characterization of nickel subjected to dynamic plastic deformation', Scr. Mater., 2012, 66 , $335-338$.

17. G. Kurdjumow and G. Sachs: 'About the mechanism of hardening steel', Z. Phys, 1930, 64, $325-343$.

18. S. Morito, H. Tanaka, R. Konishi, T. Furuhara and T. Maki: 'The morphology and crystallography of lath martensite in Fe-C alloys', Acta Mater., 2003, 51, 1789-1799. 
19. I.L. Dillamore, H. Katoh and K. Haslam: 'The Nucleation of recrystallisation and the development of textures in heavily compressed iron-carbon alloys', Texture, 1974, 1, $151-156$.

20. H. Hu: 'Texture of metals', Texture, 1974, 1, 233-258.

21. D. Raabe: 'Experimental investigation and simulation of crystallographic rolling textures of Fe-11Cr steel', Mater. Sci. Technol., 1995, 11, 985-993.

22. D. Ostwaldt, J.R. Klepacko and P. Klimanek: 'Compression tests of polycrystalline alphairon up to high strains over a large range of strain rates', J. Phys. IV, 1997, 7, 385-390.

23. J.R. Bowen, O.V. Mishin, P.B. Prangnell and D. Juul Jensen: 'Orientation correlations in aluminium deformed by ECAE', Scr. Mater., 2002, 47, 289-294.

24. O.V. Mishin, L. Östensson and A. Godfrey: 'Comparative microstructural characterization of a friction-stir-welded aluminum alloy using TEM and SEM-based techniques', Metall. Mater. Trans. A, 2006, 37, 489-496. 
Table 1: Chemical composition (wt. \%) of modified $9 \mathrm{Cr}-1$ Mo steel as determined by glow discharge optical emission spectroscopy

\begin{tabular}{cccccccccccc}
\hline $\mathrm{C}$ & $\mathrm{Cr}$ & $\mathrm{Mo}$ & $\mathrm{V}$ & $\mathrm{Ni}$ & $\mathrm{Nb}$ & $\mathrm{W}$ & $\mathrm{Si}$ & $\mathrm{Mn}$ & $\mathrm{P}$ & $\mathrm{S}$ & $\mathrm{Fe}$ \\
\hline 0.11 & 8.20 & 0.98 & 0.20 & 0.16 & 0.07 & 0.01 & 0.31 & 0.51 & 0.02 & $<0.01$ & Balance
\end{tabular}

Table 2: Microstructural parameters determined using EBSD (boundary spacings as average intercept length along the ND for different types of boundaries, fraction of high angle boundaries, and recrystallized fraction) and Vickers hardness

\begin{tabular}{lccccccccc}
\hline \multicolumn{1}{c}{ Condition } & $\begin{array}{c}d_{\left(\theta>2^{\circ}\right)} \\
(\mu \mathrm{m})\end{array}$ & $\begin{array}{c}d_{\mathrm{LAB}} \\
(\mu \mathrm{m})\end{array}$ & $\begin{array}{c}d_{\mathrm{LAB}}^{*} \\
(\mu \mathrm{m})\end{array}$ & $\begin{array}{c}d_{\mathrm{HAB}} \\
(\mu \mathrm{m})\end{array}$ & $\begin{array}{c}d_{\mathrm{MBB}} \\
(\mu \mathrm{m})\end{array}$ & $\begin{array}{c}d_{\mathrm{MBB}}^{*} \\
(\mu \mathrm{m})\end{array}$ & $\begin{array}{c}f_{\mathrm{HAB}} \\
(\%)\end{array}$ & $f_{\mathrm{RX}}(\%)$ & $\mathrm{HV} 1$ \\
\hline As-received & 1.11 & 2.04 & - & 2.43 & 5.9 & - & 46 & - & $205 \pm 2$ \\
DPD & 0.21 & 0.25 & - & 0.81 & 7.4 & - & 23 & - & $304 \pm 5$ \\
QSC & 0.29 & 0.38 & - & 0.93 & 8.5 & - & 29 & - & $271 \pm 6$ \\
$\mathrm{DPD}+675^{\circ} \mathrm{C} 1 \mathrm{~h}$ & 0.37 & 0.60 & 0.55 & 0.96 & 8.8 & 8.6 & 38 & 8 & $231 \pm 9$ \\
$\mathrm{QSC}+675^{\circ} \mathrm{C} 1 \mathrm{~h}$ & 0.43 & 0.61 & 0.60 & 1.45 & 10.6 & 10.6 & 30 & 2 & $243 \pm 5$ \\
$\mathrm{DPD}+700^{\circ} \mathrm{C} 1 \mathrm{~h}$ & 3.4 & 15.2 & 1.22 & 4.4 & 60 & 37.6 & 78 & 95 & $164 \pm 7$ \\
$\mathrm{QSC}+700^{\circ} \mathrm{C} 1 \mathrm{~h}$ & 0.61 & 0.88 & 0.83 & 1.97 & 12.9 & 12.7 & 31 & 6 & $229 \pm 8$ \\
\hline
\end{tabular}




\section{Figure captions}

Fig. 1. Microstructure of the as-received condition: (a) a bright field TEM image (arrows indicate some of the carbides present); and (b) a schematic illustration of the region shown in (a) with martensite block boundaries and cell boundaries shown by bold and thin lines, respectively. The ND is horizontal.

Fig. 2. Misorientation maps obtained by EBSD: (a) as-received sample; (b) DPD sample; and (c) QSC sample. Thin gray and bold dark lines show LABs $\left(2-15^{\circ}\right)$ and HABs $\left(>15^{\circ}\right)$, respectively. Boundaries with either of the $60^{\circ}\langle 111\rangle, 60^{\circ}\langle 110\rangle$, or $49.5^{\circ}\langle 110\rangle$ misorientations are shown in red. The ND is horizontal.

Fig. 3. Distribution of misorientation angles obtained by EBSD: (a) as-received sample; (b) DPD sample; and (c) QSC sample.

Fig. 4. Inverse pole figures showing the crystallographic texture: (a) as-received material, (b) DPD sample; (c) QSC sample; (d) DPD sample after annealing at $700{ }^{\circ} \mathrm{C}$ for $1 \mathrm{~h}$; and (e) QSC sample after annealing at $700{ }^{\circ} \mathrm{C}$ for $1 \mathrm{~h}$. Numbers represent the maximum intensity for different texture components. Contour lines are given at 1, 2, 3, 4, and $5 \times$ random.

Fig. 5. TEM images of the deformed microstructure: (a) DPD sample; and (b) QSC sample. The ND is approximately horizontal.

Fig. 6. EBSD maps from the samples annealed at $675^{\circ} \mathrm{C}$ for $1 \mathrm{~h}$ : (a) DPD sample; and (b) QSC sample. Thin gray and bold dark lines show LABs $\left(2-15^{\circ}\right)$ and HABs $\left(>15^{\circ}\right)$, respectively. Boundaries with either $60^{\circ}\langle 111\rangle, 60^{\circ}\langle 110\rangle$, or $49.5^{\circ}\langle 110\rangle$ misorientation are shown in red. Recrystallized grains are shown in yellow. The ND is horizontal.

Fig. 7. EBSD maps from the samples annealed at $700{ }^{\circ} \mathrm{C}$ for $1 \mathrm{~h}$ : (a) DPD sample; and (b) QSC sample. Thin gray and bold dark lines show LABs $\left(2-15^{\circ}\right)$ and HABs $\left(>15^{\circ}\right)$, respectively. Boundaries with either $60^{\circ}\langle 111\rangle, 60^{\circ}\langle 110\rangle$, or $49.5^{\circ}\langle 110\rangle$ misorientation are shown in red. Recrystallized grains are shown in yellow. The ND is horizontal. 
Fig.1

Click here to download high resolution image
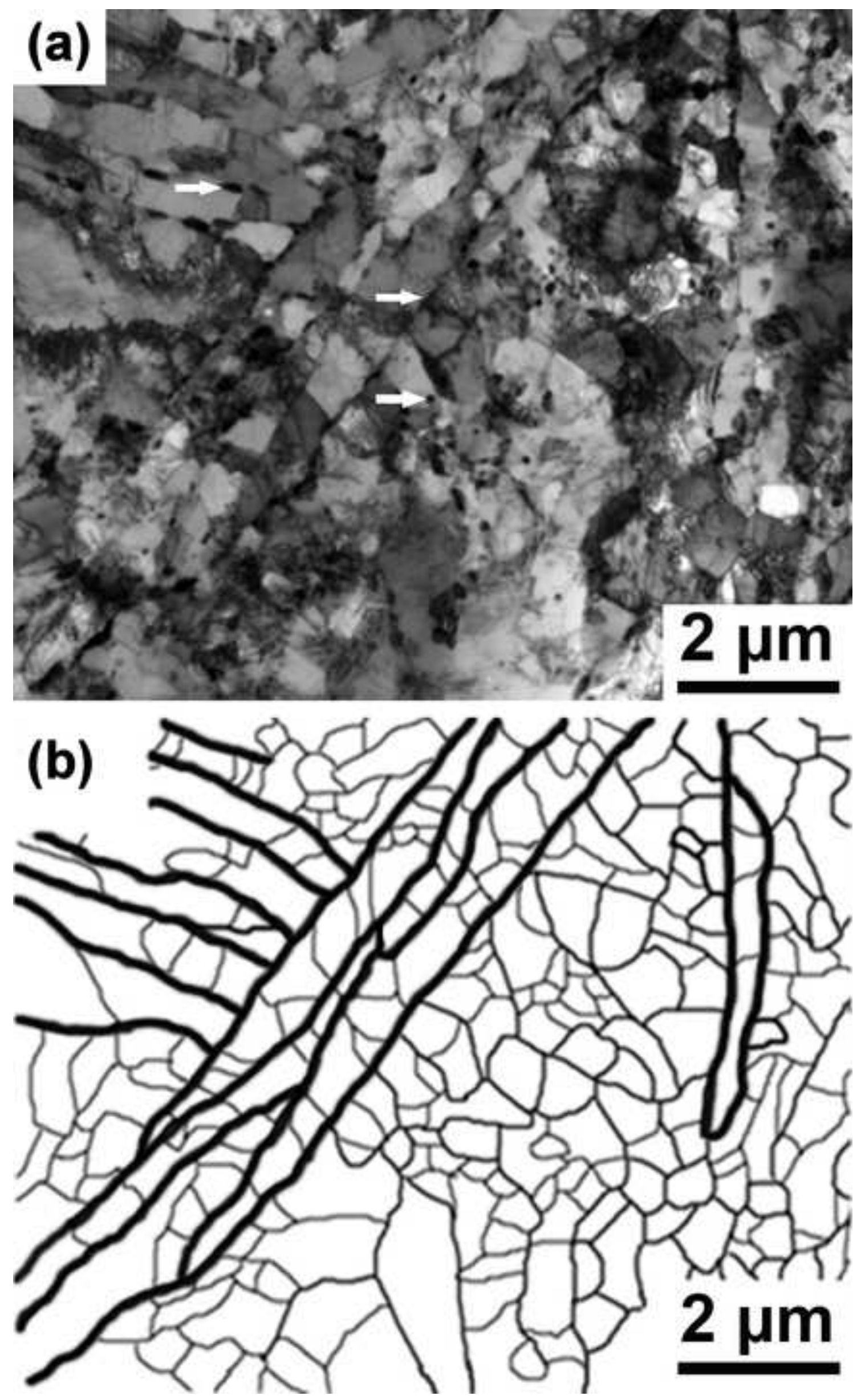
Fig. 2

Click here to download high resolution image
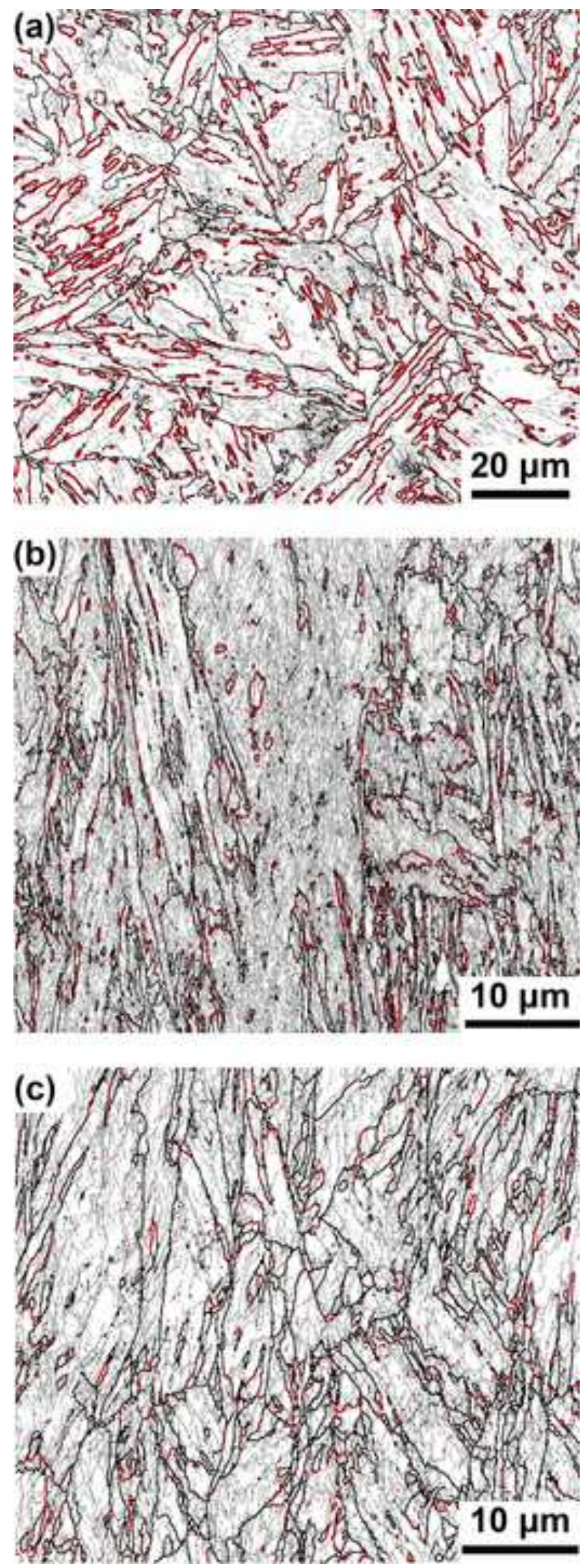

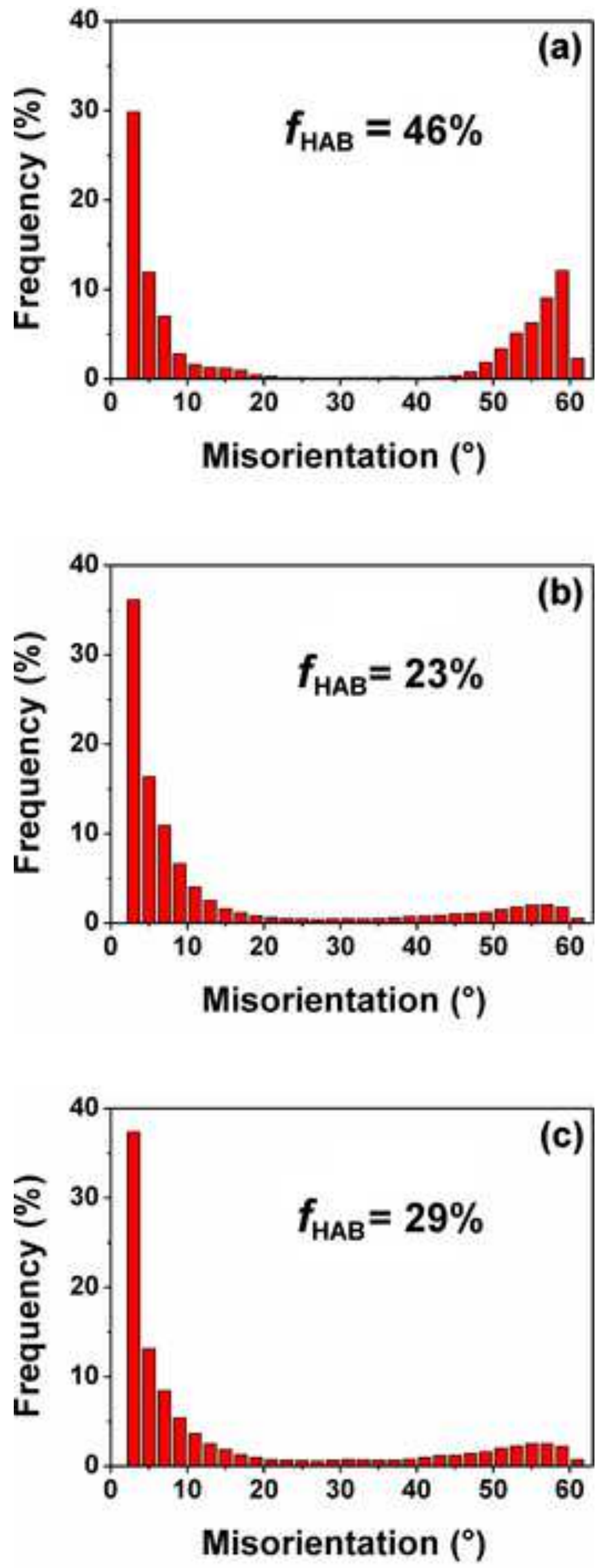


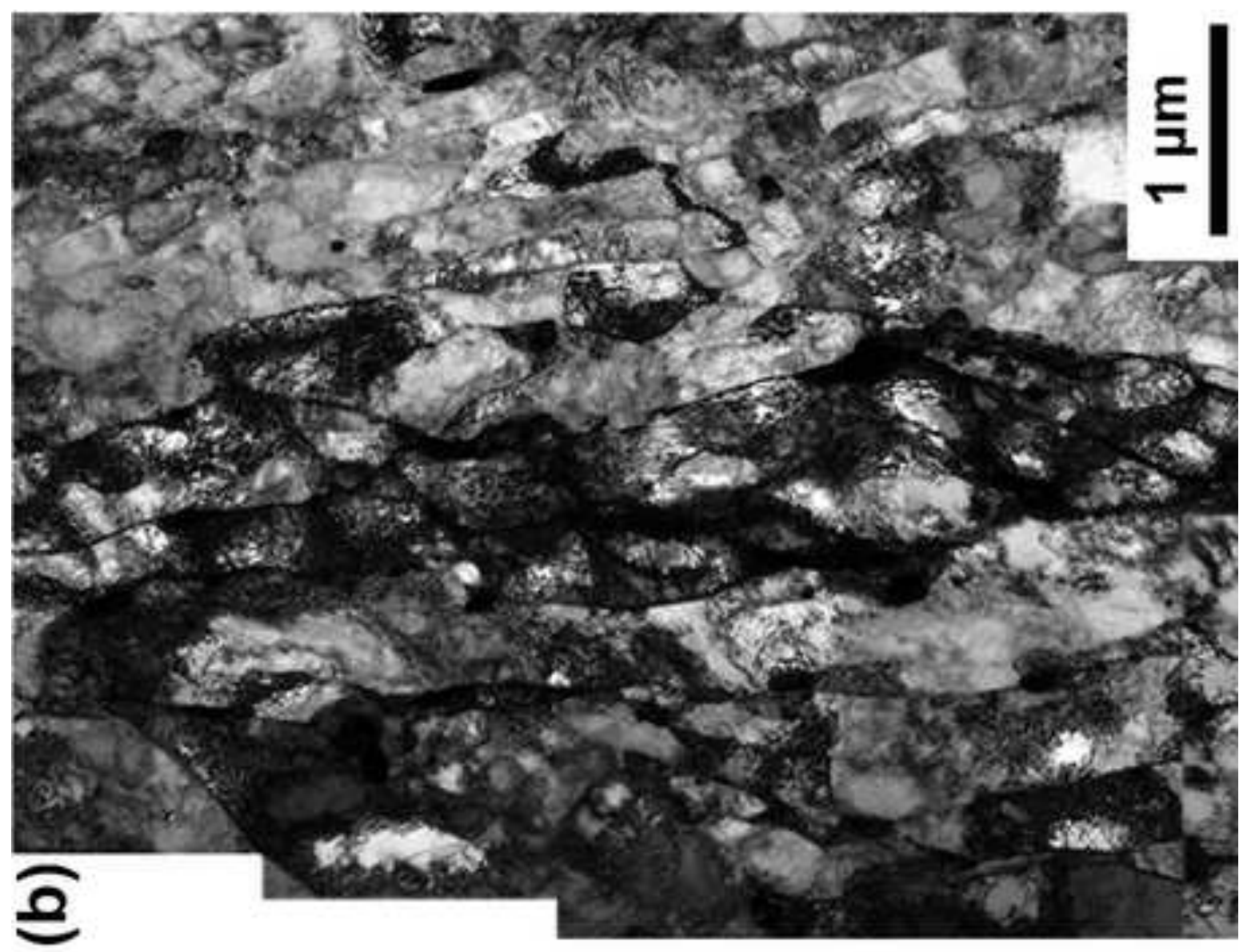

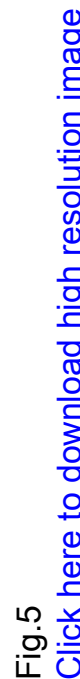

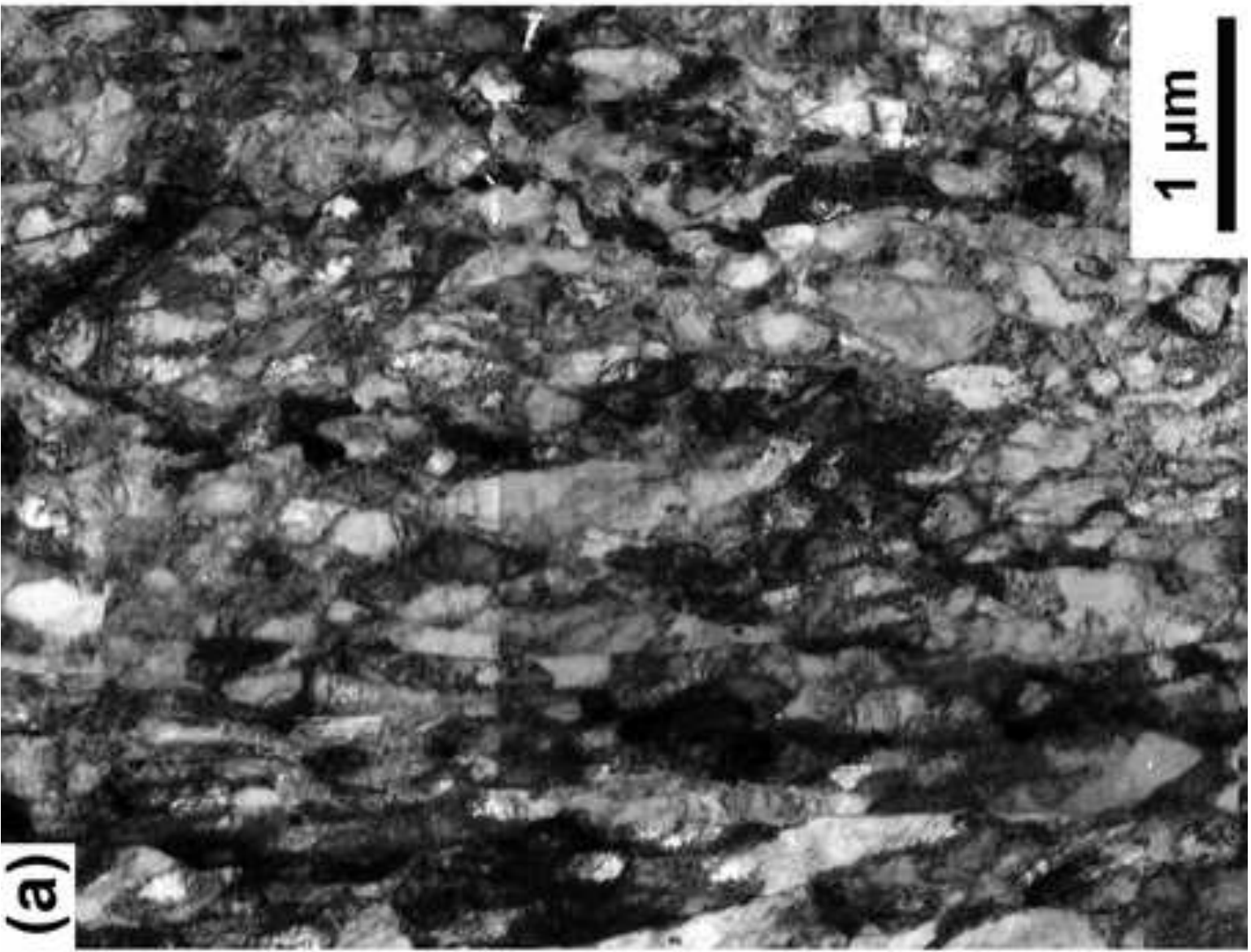



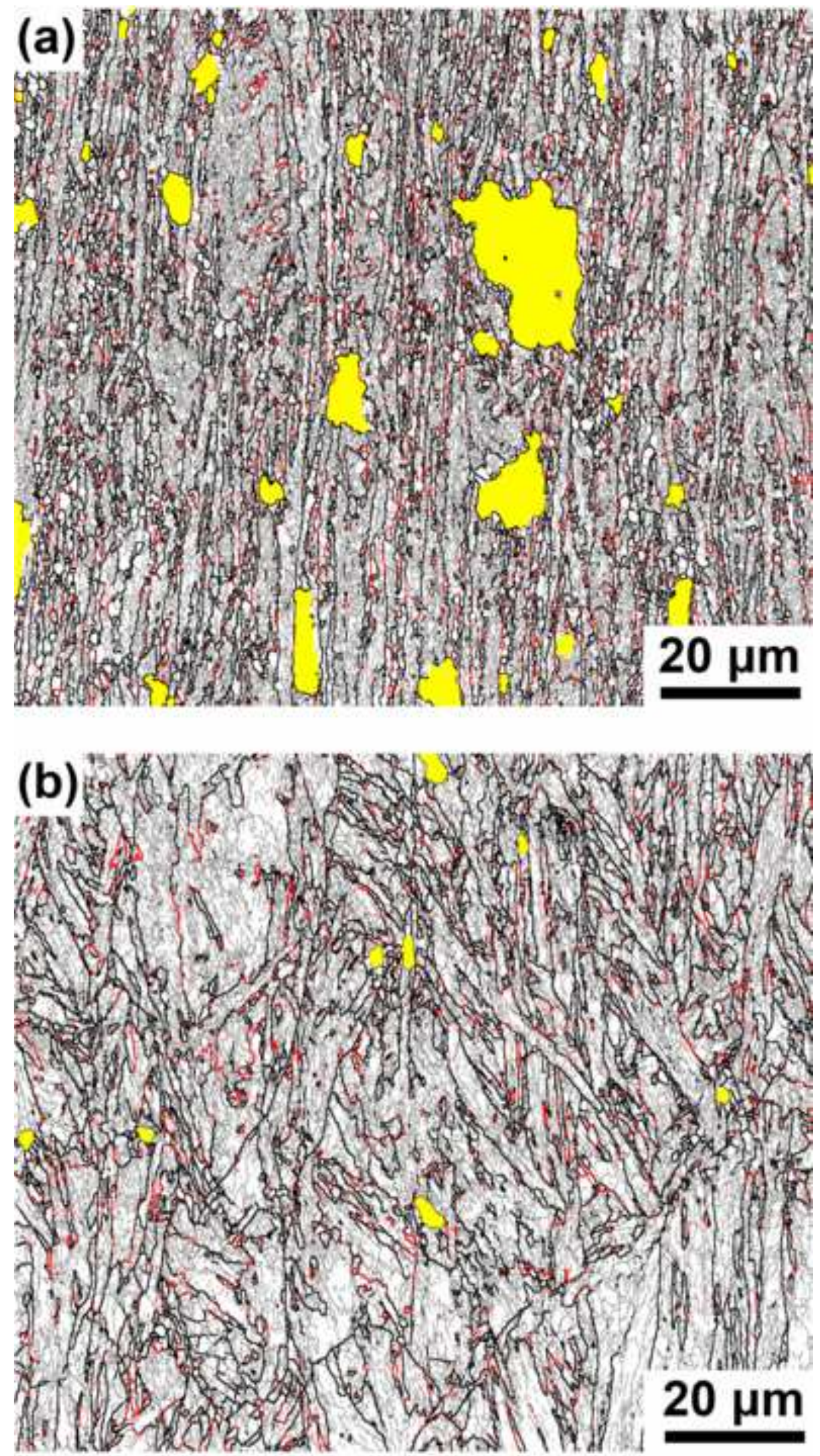


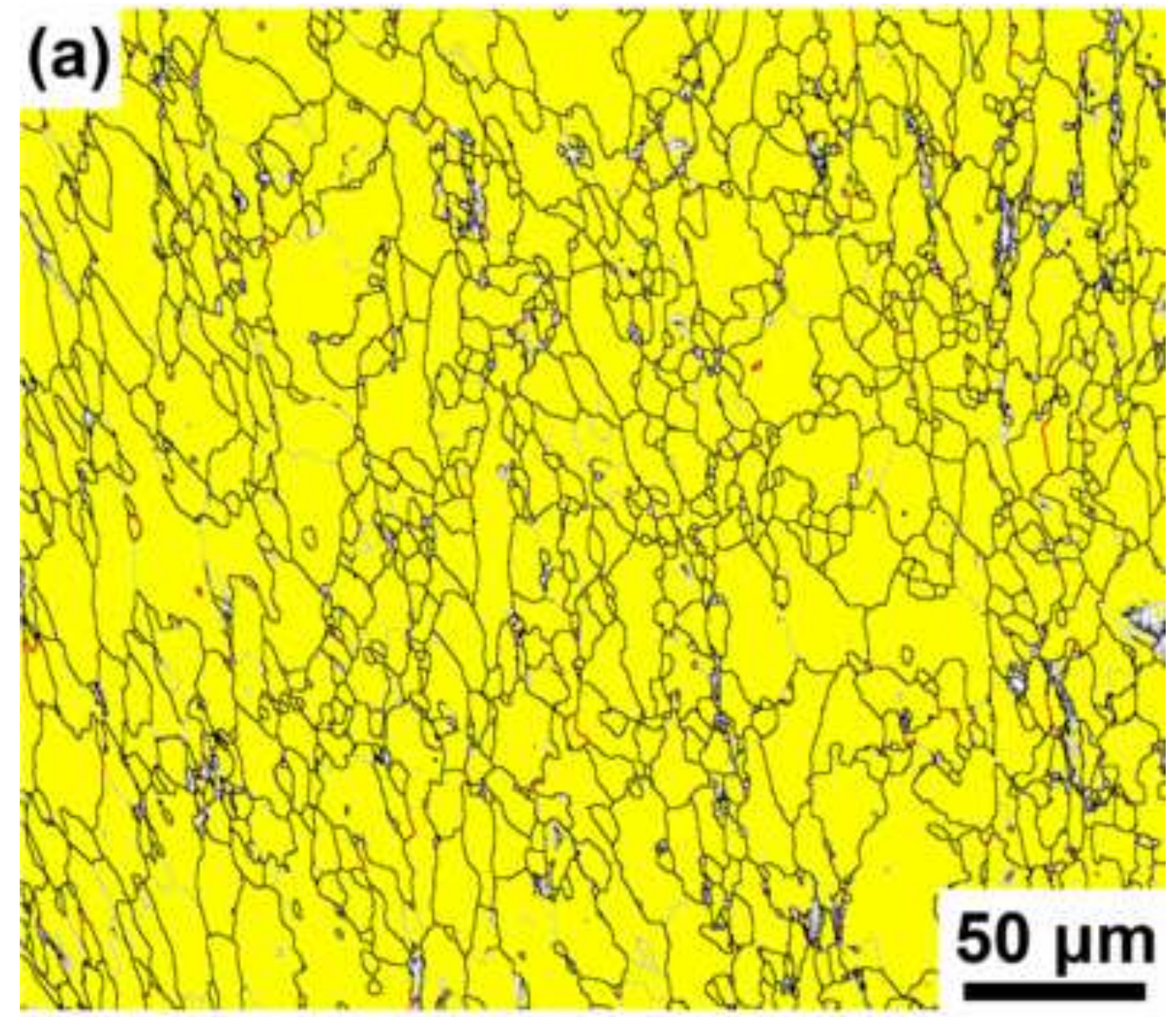

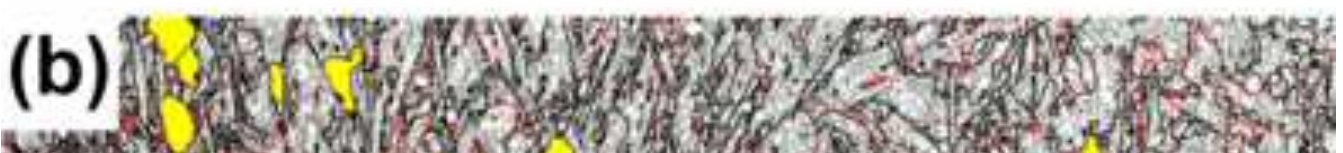

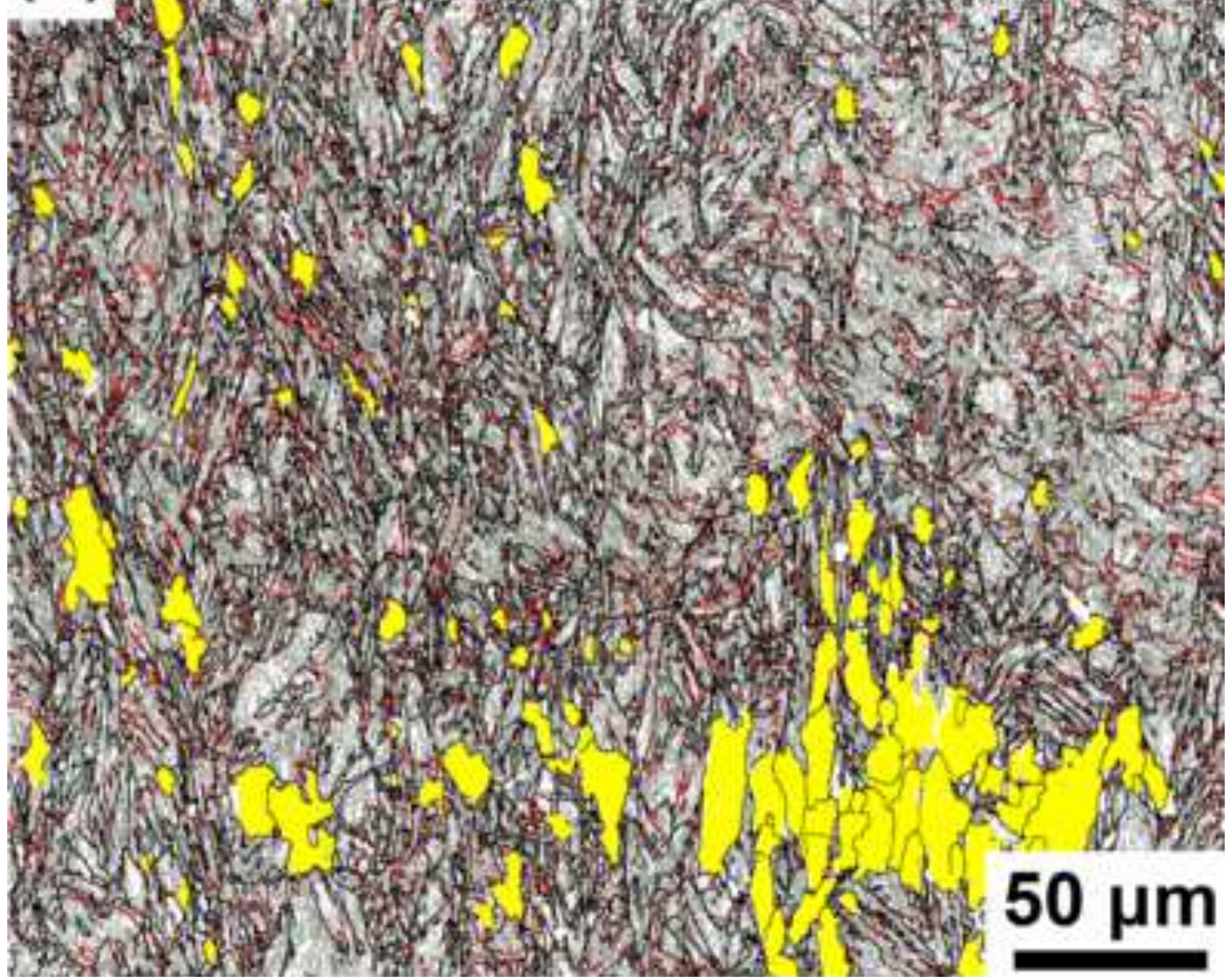

